\title{
Analisis perbandingan penurunan pondasi telapak pada empat lokasi
}

\author{
Cece Suhendi a,1, ${ }^{*}$, Resa Susanti Rahmawati a,2, Angga Setiawan b,3 \\ a Universitas Nusa Putra, Jl. Raya Cibatu Cisaat No.21, Cibolang Kaler, Kec. Cisaat, Sukabumi Regency, Jawa Barat 43155, Indonesia \\ ${ }^{b}$ Universitas 17 Agustus 1945, Semarang, Indonesia \\ 1 cece.suhendi@nusaputra.ac.id *; 2 resa.susanti_ts16@nusaputra.ac.id; 3angga.setyawan_17@gmail.com \\ * Corresponding Author
}

Received 25 February 2015; revised 8 May 2015; acceted13 May 2015

\begin{abstract}
ABSTRAK
Setiap wilayah memiliki nilai penurunan yang berbeda, hal ini dipengaruhi oleh daya dukung tanah di masing-masing, oleh karena itu untuk menghasilkan konstruksi pondasi yang lebih efisien maka dilakukan analisis terhadap tanah di kabupaten Sukabumi dengan sampel tanah Kp Cicantayan, Kp pamoyanan, Kp Cidadap dan Kp Cikaramat untuk mengetahui dampaknya terhadap kemungkinan penurunan yang dapat terjadi pada pondasi yang digunakan. Untuk masalah tersebut perlu adanya penelitian terhadap penurunan dan daya dukung tanah dengan data pengujian tanah. Berdasarkan hasil perhitungan penurunan pondasi segera diketahui penurunan pondasi telapak paling tinggi terjadi di Kp. Cikaramat, Desa Sukamanis Kec. Kadudampit dengan nomor sampel TB 3-02 1 sebesar 1,01 mm dengan faktor keamanan 4,42 dan penurunan terkecil terdapat pada Desa Bojong Cicantayan sebesar 0,101 mm dengan faktor keamanan 6,5. Dari hasil analisis aplikasi Eurocode terhadap desain pondasi telapak yang direncanakan dinyatakan aman dengan nilai batas daya dukung maksimal yang lebih besar daripada nilai kapasitas daya dukung tanah pada desain pondasi
\end{abstract}

\section{Comparative analysis of foundation decrease at four locations}

\section{ABSTRACT}

Each region has a different subsidence value, this is influenced by the carrying capacity of the soil in each, Therefore, to produce a more efficient foundation construction, an analysis of the soil in Sukabumi district was carried out with soil samples from Kp Cicantayan, Kp Pamoyanan, Kp Cidadap and Kp Cikaramat to determine their impact on possible subsidence that could occur in the foundation used. For this problem, it is necessary to research the settlement and carrying capacity of the soil with soil testing data. Based on the results of the calculation of the settlement of the foundation, it is immediately known that the highest settlement of the palm foundation occurs in Kp. Cikaramat, Desa Sukamanis Kec. Kadudampit with sample numberTB 3-02 1 is $1.01 \mathrm{~mm}$ with a safety factor of 4.42 and the smallest decrease is in Bojong Cicantayan village of $0.101 \mathrm{~mm}$ with a safety factor of 6.5. From the results of the analysis of the Eurocode application of the planned tread foundation design, it is stated that it is safe with a maximum carrying capacity limit value greater than the value soil bearing capacity in foundation design.

\section{Pendahuluan}

Pondasi merupakan bagian dari suatu sistem rekayasa yang meneruskan beban yang ditopang oleh pondasi dan beratnya sendiri ke dalam tanah dan batuan yang terletak di bawahnya [1]. Jenis pondasi dipengaruhi oleh beberapa faktor, antara lain: Keadaan tanah pondasi yang meliputi jenis tanah, daya dukung tanah, kedalaman tanah keras dan lainnya, batasan-batasan akibat konstruksi tersebut.Pondasi berfungsi sebagai dasar bangunan dan memiliki beberapa jenis yang dapat diaplikasikan untuk membangun suatu bangunan,salah satunya yaitu pondasi telapak atau biasa disebut pondasi foot plate [2] 
Adapun penelitian sebelumnya adalah Analisis penurunan pondasi dilakukan untuk mengantisipasi penurunan pondasi yang berlebihan sehingga dapat mencegah terjadinya kegagalan struktur bangunan yang diakibatkan beban yang berlebih [3]. Berikut hasil perhitungan penurunan segera terhadap tanah Desa Bojong Cicantayan, Kp Pamoyanan Desa Banyuwangi Kecamatan Cibitung, Kp Cibarengkok Desa Cidadap Kecamatan Simpenan dan Kp Cikaramat Desa Sukamanis Kecamatan Kadudampit dengan mengetahui Tekanan pondasi neto, Penurunan Segera pada sudut luasan pondasi dan Penurunan segera pada pusat luasan. Dengan menggunakan nilai beban aksial dari bangunan $(\mathrm{P})=155,254 \mathrm{Kn}$. Nilai Ip yang digunakan dari grafik faktor pengaruh penurunan di sudut luasan segi empat fleksibel (Terzaghi) dengan panjang dan lebar pondasi $(\mathrm{L} / \mathrm{B})=1,6 / 1,6=1$ Maka diperoleh nilai 0,56 . Setiap lokasi memiliki nilai penurunan pondasi yang berbeda, hal ini dipengaruhi oleh daya dukung tanah di masing-masing lokasi, Sukabumi terdiri dari berbagai jenis tanah oleh karena itu untuk menghasilkan konstruksi pondasi yang lebih efisien maka dilakukan analisis terhadap tanah di kabupaten Sukabumi dengan beberapa sampel tanah di wilayah yang berbeda untuk mengetahui dampaknya terhadap kemungkinan penurunan yang dapat terjadi pada pondasi yang digunakan, sehingga perlunya dianalisis lebih lanjut bagaimana daya dukung tanah terhadap pondasi telapak di lokasi penelitian kemudian berapakah perbandingan penurunan Pondasi telapak di lokasi tersebut dan berapa faktor keamanan yang terjadi terhadap beban bangunan diatasnya. Dengan begitu kita dapat mengetahui lokasi mana yang memiliki nilai penurunan yang paling kecil untuk dijadikan lokasi pembangunan yang lebih efektif dan efisien [4]. Faktor keamanan pondasi yang terjadi akibat beban kerja diatasnya yang diasumsikan dengan bangunan rumah 2 lantai seperti penjelasan diatas. Berikut faktor keamanan yang terjadi pada pondasi telapak dengan menggunakan delapan sampel tanah dan 4 lokasi dengan menggunakan metode perhitungan Meyerhof [5].

\section{Metode}

Metode yang digunakan dalam penelitian ini adalah Metode Kuantitatif yang mana data penelitian berupa nilai-nilai dan analisis menggunakan statistic [6]. Penelitian ini dimulai dengan menentukan jenis tanah berdasarkan sistem klasifikasi tekstur dan klasifikasi USCS [7] dengan menggunakan nilai Konsistensi (Batas Atterberg) dan Distribusi ukuran butir (ASTM) dari Lokasi Objek penelitian yaitu Desa Bojong Cicantayan, Kp Pamoyanan Desa Banyuwangi Kec. Cibitung, Kp Cibarengkok Desa Cidadap Kec. Simpenan, Kp Cikaramat Desa Sukamanis Kec. Kadudampit, data yang digunakan merupakan data sekunder hasil pengujian terdahulu yang berasal dari Laboratorium PU Kabupaten Sukabumi. Kemudian menentukan dimensi pondasi telapak dengan mengetahui kapasitas daya dukung menggunakan persamaan metode Meyerhof dan Terzaghi untuk mengetahui apakah dimensi pondasi yang digunakan tersebut aman digunakan pada lokasi penelitian sebagai bahan untuk mengetahui penurunan segera terhadap lokasi penelitian, Pembebanan menggunakan data maksimum hasil analisis perhitungan beban rumah 2 lantai yang akan direncanakan menggunakan aplikasi pendukung analisis struktur Selanjutnya tentukan faktor keamanan pada pondasi telapak [8]. Sebagai hasil akhir dapat dilihat pada Table 1. Hasil penelitian untuk memastikan hasil desain pondasi terhadap daya dukung tanah maka digunakan apliksasi Eurocode.

Tabel 1. Data Tanah

\begin{tabular}{|c|c|c|c|c|c|c|c|c|c|}
\hline \multirow{2}{*}{ Parameter } & \multicolumn{2}{|c|}{$\begin{array}{c}\text { Desa } \\
\text { Bojong }\end{array}$} & \multicolumn{2}{|c|}{$\begin{array}{c}\text { Kp } \\
\text { Pamoyanan }\end{array}$} & \multicolumn{2}{|c|}{$\begin{array}{c}\text { Kp } \\
\text { Cibarengkok }\end{array}$} & \multicolumn{2}{|c|}{ Kp Cikaramat } & \multirow{2}{*}{ Satuan } \\
\hline & $\mathbf{I}$ & II & I & II & I & II & I & II & \\
\hline Berat Jenis & 2.26 & 2.18 & 2.18 & 2.19 & 2.18 & 2.22 & 2.19 & 2.24 & $\mathrm{gr} / \mathrm{cm}^{3}$ \\
\hline Kohesi & 0.08 & 0.04 & 0.07 & 0.05 & 0.010 & 0.04 & 0.11 & 0.04 & $\mathrm{Kg} / \mathrm{cm}^{2}$ \\
\hline Sudut Geser & 14,43 & 21,11 & 17.35 & 23.45 & 18.31 & 24.68 & 18.31 & 25.54 & $\left(\ldots{ }^{\circ}(\right.$ \\
\hline Dalam Tahanan Konus & 50.00 & 50.00 & 30.00 & 30.00 & 40.00 & 40.00 & 50.00 & 50.00 & $\mathrm{Kg} / \mathrm{cm}^{2}$ \\
\hline
\end{tabular}

Sumber : Laboratorium PU Kabupaten Sukabumi 
Berikut ini perancagan denah lantai bawah, atas, denah stuktur lantai bawah, atas dan juga hasil perspektif 2D pada Gambar 1.

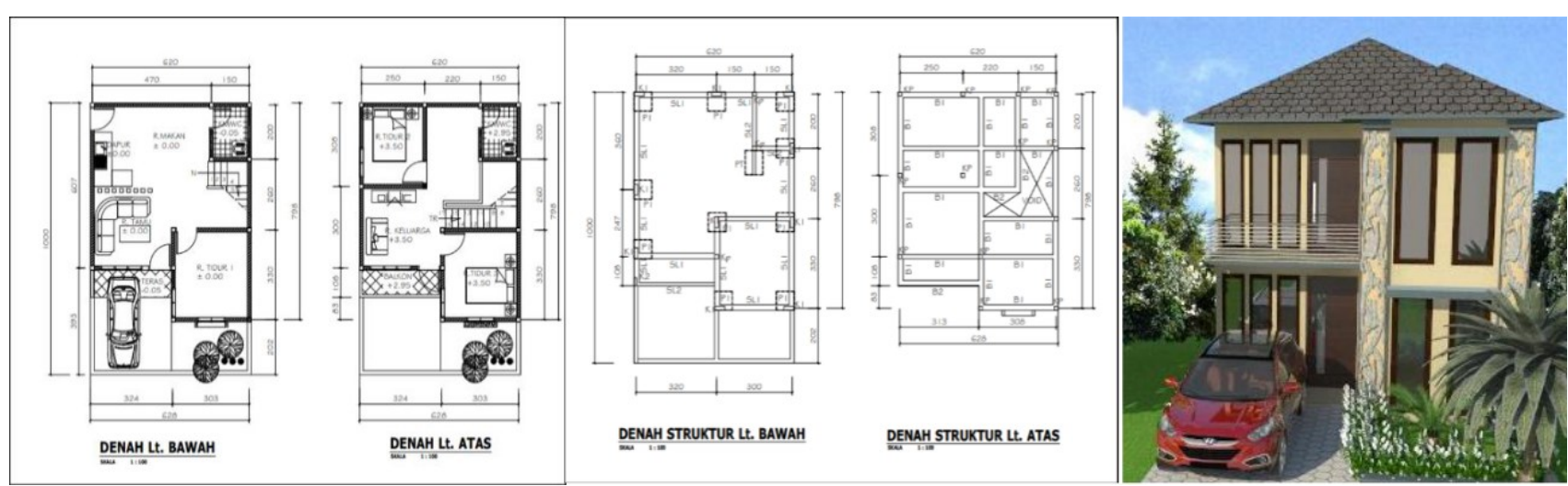

Gambar 1. Denah Lantai dan Tampak Perspektif Perencanaan rumah 2 lantai

Data output P berjumlah 155.2, nilai M2 1.7468 dan juga M3 sebesar 31.82. untuk lebih jelasnya dapat dilihat pada Tabel 2.

Tabel 2. Data Output pembebanan Rumah 2 Lantai

\begin{tabular}{ccc}
\hline $\mathbf{P}$ & M2 & M3 \\
\hline $\mathrm{KN}$ & $\mathrm{KN}-\mathrm{m}$ & $\mathrm{KN}-\mathrm{m}$ \\
155,254 & 1,7468 & 31,8259 \\
\hline
\end{tabular}

Setelah semua data yang dibutuhkan lengkap maka selanjutnya dilakukan perhitungan dengan persamaan sebagai berikut; Kapasitas Dukung Ultimit tanah berdasarkan persamaan.

Terzaghi qu $=$ c. Nc $\cdot(1+0,3 \cdot B / L)+$ Df.g. $N_{q}+0,5 \cdot B \cdot N_{g} \cdot(1-0,2 \cdot B / L)[9]$

Kapasitas Dukung Tanah berdasarkan persamaan Meyerhof [10]

$\mathrm{q}_{\mathrm{a}}=\mathrm{q}_{\mathrm{c}} / 33 \cdot[(\mathrm{B}+0,3) / \mathrm{B}]^{2} \cdot \mathrm{Kd}_{\mathrm{d}}\left(\right.$ Dalam $\left.\mathrm{kg} / \mathrm{cm}^{2}\right)$

$\mathrm{K}_{\mathrm{d}}=1+0,33 . \mathrm{Df} / \mathrm{B}$

\section{Rumus penurunan segera}

Rumus Tekanan pondasi neto $\mathrm{qn}=\mathrm{q}-\partial \mathrm{b}$ Df; Penurunan segera pada sudut luasan $\left(1-\mu^{2}\right)$. Dengan Si merupkan penurunan segera $(\mathbf{m})$, qn adalah tambahan tegangan $(\mathrm{kN} / \mathrm{m} 2)$, lembar area pembedaan (m), Ip adalah faktor pengaruh dan $\boldsymbol{\mu}$ merupakan angka poisson. Faktor keamanan dengan membandingkan daya dukung dengan tegangan maksimum: $\mathrm{SF}=\mathrm{qu} / \mathrm{q}_{\max }$. Dibanding dengan beban vertikal ekivalen, nilai Qu ini memberikan;

$\mathrm{SF}=\mathrm{Qu} / \mathrm{Q}[1]$

Flowchart dapat dilihat pada Gambar 2 yaitu berupa perencananan, pengumpulan data skunder dengan data pengujian tanah dan nilai maksimum. Tahapannya berikutnya merupakan menentukan dimensi pondasi, lalu melakukan kapasitas daya dukung pondasi, penurunan segera dan menentukan faktor kemanan pondasi. 


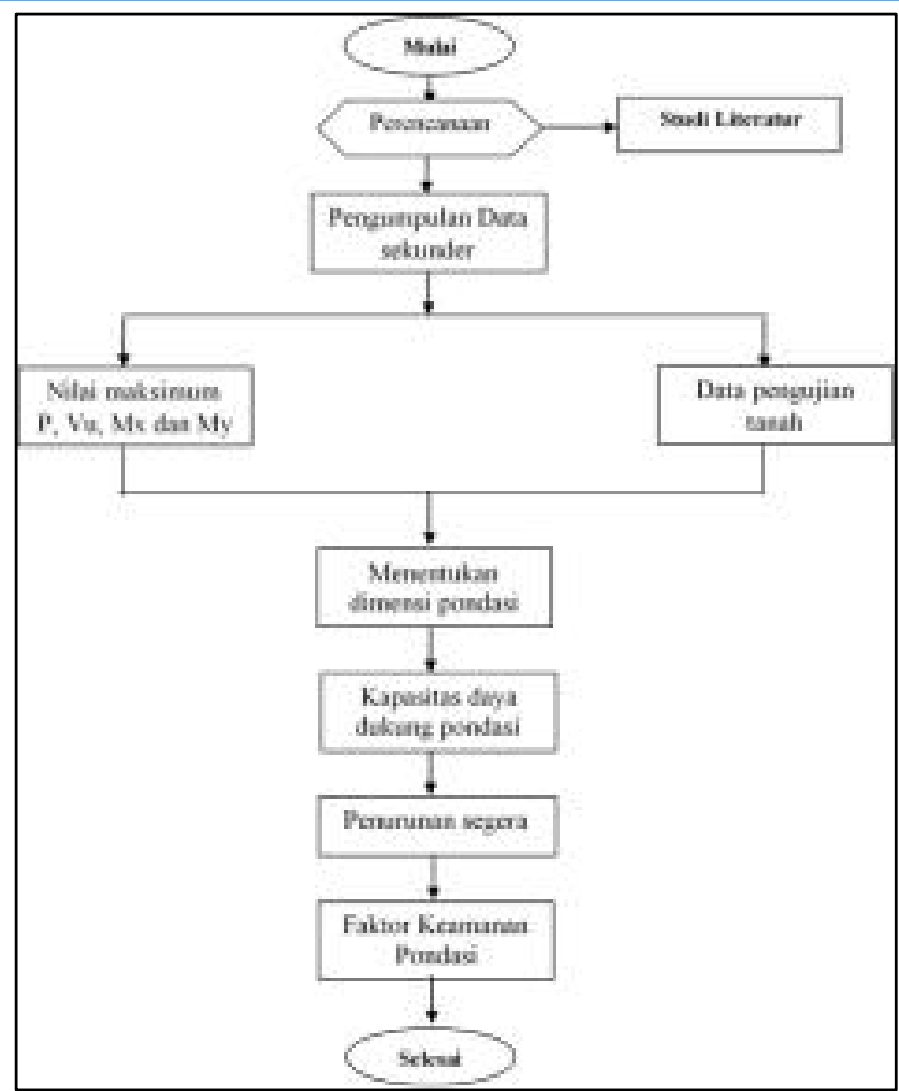

Gambar 2. Bagan alir penelitian

\section{Hasil dan Pembahasan}

Berdasarkan hasil klasifikasi tekstur dan klasifikasi USCS dengan menggunakan nilai Konsistensi (Batas Atterberg) dan Distribusi ukuran butir (ASTM) dari Lokasi Objek penelitian yaitu Desa Bojong Cicantayan, Kp Pamoyanan Desa Banyuwangi Kec.Cibitung, Kp Cibarengkok Desa Cidadap Kec. Simpenan, Kp Cikaramat Desa Sukamanis Kec. Kadudampit menunjukan jenis tanah pada ke empat daerah tersebut tergolong kedalam jenis tanah lempung, berbutir halus lebih dari $50 \%$ fraksi berukuran lebih kecil dari 0,075 mm). diklasifikasikan $\mathrm{MH}$ dan $\mathrm{OH}$ (Mohs, High Consistency) dan $\mathrm{OH}$ (Organic, High Consistency) yaitu tanah lanau organik dan lempung organik dengan plastisitas sedang sampai tinggi mengetahui kapasitas daya dukung menggunakan persamaan metode Meyerhof dan Terzaghi. Hasil Kapasitas daya dapat dilihat pada Table 3 dukung pondasi dihitung dengan metode statis berdasarkan data sondir dan parameter tanah $(\gamma, \mathrm{c}$ dan $)$. Data tanah yang berupa data sondir. Berdasarkan hasil perhitungan daya dukung tanah melalui persamaan Meyerhof dan Terzaghi maka dimensi pondasi 1,6m $\mathrm{x} 1,6 \mathrm{~m}$ dengan kedalaman pondasi $2 \mathrm{~m}$ memenuhi syarat aman terhadap beban yang bekerja pada pondasi.

Tabel 3 Nilai daya dukung pondasi terhadap sampel tanah

\begin{tabular}{ccccccccc}
\hline \multirow{2}{*}{ Tegangan } & \multicolumn{2}{c}{ Desa bojong } & \multicolumn{2}{c}{ Kp pamoyanan } & \multicolumn{2}{c}{ Kp cibarengkok } & \multicolumn{2}{c}{ Kp cikaramat } \\
\cline { 2 - 8 } & I & II & I & II & I & II & I & I \\
\hline$\sigma$ Maks $\left(\mathrm{KN} / \mathrm{m}^{2}\right)$ & 154,697 & 153,354 & 153,354 & 153,254 & 153,354 & 154,034 & 153,524 & 154,425 \\
\multirow{2}{*}{$\sigma \mathrm{Jjin}\left(\mathrm{KN} / \mathrm{m}^{2}\right)$} & 284,17 & 284,17 & 170,50 & 203,20 & 227,33 & 227,33 & 284,17 & 284,17 \\
& $\mathrm{OK}$ & $\mathrm{OK}$ & $\mathrm{OK}$ & $\mathrm{OK}$ & $\mathrm{OK}$ & $\mathrm{OK}$ & $\mathrm{OK}$ & $\mathrm{OK}$ \\
& & & & & & &
\end{tabular}

Berdasarkan hasil perhitungan Daya dukung pondasi yang telah dilakukan daya dukung recana $(\sigma$ maks)lebih kecil dari daya dukuung aktual ( $\sigma$ ijin), maka daya dukung pondasi telapak pada ke empat lokasi telah memenuhi syarat yang diijinkan dapat dilihat pada Gambar 3. 


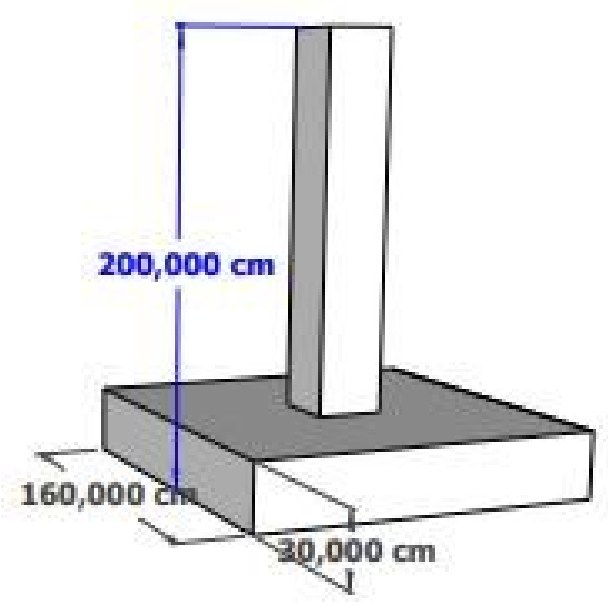

Gambar 3. Dimensi pondasi telapak

\subsection{Penurunan Segera}

Analisis penurunan pondasi dilakukan untuk mengantisipasi penurunan pondasi yang berlebihan sehingga dapat mencegah terjadinya kegagalan struktur bangunan yang diakibatkan beban yang berlebih. Berikut hasil perhitungan penurunan segera terhadap tanah Desa Bojong Cicantayan, Kp Pamoyanan Desa Banyuwangi Kecamatan Cibitung, Kp Cibarengkok Desa Cidadap Kecamatan Simpenan dan Kp Cikaramat Desa Sukamanis Kecamatan Kadudampit dengan mengetahui Tekanan pondasi neto, Penurunan Segera pada sudut luasan pondasi dan Penurunan segera pada pusat luasan. Dengan menggunakan nilai beban aksial dari bangunan $(P)=155,254 \mathrm{Kn}$. Nilai Ip yang digunakan dari grafik faktor pengaruh penurunan di sudut luasan segi empat fleksibel (Terzaghi) dengan panjang dan lebar pondasi $(\mathrm{L} / \mathrm{B})=1,6 / 1,6=1$ Maka diperoleh nilai 0,56. Penurunan segera dapat dilihat pada Tabel 4.

Tabel 4 Nilai penurunan segera pada lokasi

\begin{tabular}{cccc}
\hline Lokasi & No Sampel & $\begin{array}{c}\text { Penurunan segera } \\
\text { pada luasan }\end{array}$ & $\begin{array}{c}\text { Penurunan } \\
\text { Pada pusat luasan }\end{array}$ \\
\hline Desa Bojong, Cicantayan & TB 2-01 & $0.476 \mathrm{~mm}$ & $0.952 \mathrm{~mm}$ \\
Kp. Pamoyanan, Desa Banyuwangi Kec. & TB 2-01 2 & $0,508 \mathrm{~mm}$ & $0,101 \mathrm{~mm}$ \\
Cibitung & TB 2-02 2 & $0,467 \mathrm{~mm}$ & $0,952 \mathrm{~mm}$ \\
Kp. Cibarengkok Desa Cidadap Kec. & TB 3-01 1 & $0,509 \mathrm{~mm}$ & $1 \mathrm{~mm}$ \\
Simpenan & TB 3-01 2 & $0,509 \mathrm{~mm}$ & $1 \mathrm{~mm}$ \\
Kp. Cikaramat,Desa Sukamanis Kec. & TB 3-02 1 & $0,509 \mathrm{~mm}$ & $0,99 \mathrm{~mm}$ \\
Kadudampit & TB 3-02 2 & $0,482 \mathrm{~mm}$ & $1.01 \mathrm{~mm}$ \\
\end{tabular}

\subsection{Faktor keamanan}

Faktor keamanan pondasi yang terjadi akibat beban kerja diatasnya yang di asumsikan dengan bangunan rumah 2 lantai seperti penjelasan diatas. Berikut faktor keamanan yang terjadi pada pondasi telapak dengan menggunakan delapan sampel tanah dan 4 lokasi dengan menggunakan metode perhitungan Meyerhof. Dapat dilihat pada Tabel 5. 
Tabel 5 Faktor keaman pondasi telapak

\begin{tabular}{ccc}
\hline Lokasi & No Sampel & Faktor Kemanan pondasi \\
\hline Desa Bojong, Cicantayan & TB 2-01 1 & 7,17 \\
& TB 2-01 2 & 6,5 \\
Kp. Pamoyanan, Desa Banyuwangi & TB 2-02 1 & 5,5 \\
Kec. Cibitung & TB 2-02 2 & 7 \\
Kp. Cibarengkok Desa Cidadap Kec. & TB 3-01 1 & 5,4 \\
Simpenan & TB 3-01 2 & 8,08 \\
Kp. Cikaramat,Desa Sukamanis Kec. & TB 3-02 1 & 4,42 \\
Kadudampit & TB 3-02 2 & 9
\end{tabular}

Mengetahui hasil Desain pondasi telapak dari hasil penelitian daya dukung pondasi menggunakan Eurocode Dalam penelitian ini digunakan aplikasi untuk mengetahui hasil dari desain dan daya dukung pondasi telapak terhadap beberapa contoh tanah dari lokasi yang dijadikan sampel penelitian. Berdasarkan hasil analisis pada aplikasi dengan menggunakan nilai pembebanan $(\mathrm{Vu}, \mathrm{Mx}, \mathrm{My})$, dimensi rencana pondasi dan parameter tanah (Kohesi, berat jenis tanah dan sudut geser dalam). Berikut adalah hasil analisis menggunakan aplikasi pendukung untuk mengetahui hasil desain pondasi telapak dari hasil penelitian daya dukung pondasi telapak pada tanah yang dijadikan penelitian. Dari hasil analisis Table 6, pada aplikasi dapat diketahui nilai batas maksimum daya dukung tanah dengan nilai daya dukung yang terjadi terhadap desain pondasi yang dipakai.

Tabel 6. Output analisis Eurocode

\begin{tabular}{ccccccccc}
\hline \multirow{2}{*}{ Tegangan } & \multicolumn{2}{c}{ Desa bojong } & \multicolumn{2}{c}{ Kp pamoyanan } & \multicolumn{2}{c}{ Kp cibarengkok } & \multicolumn{2}{c}{ Kp cikaramat } \\
\cline { 2 - 9 } & I & II & I & II & I & II & I & II \\
\hline oMaks $\left(\mathrm{N} / \mathrm{mm}^{2}\right)$ & 0,103 & 0.131 & 0.114 & 0.142 & 0.120 & 0.148 & 0.120 & 0.152 \\
\multirow{2}{*}{$\sigma \mathrm{Jjin}\left(\mathrm{N} / \mathrm{mm}^{2}\right)$} & 0.145 & 0.183 & 0.159 & 0.199 & 0.168 & 0.207 & 0.169 & 0.212 \\
& $\mathrm{OK}$ & $\mathrm{OK}$ & $\mathrm{OK}$ & $\mathrm{OK}$ & $\mathrm{OK}$ & $\mathrm{OK}$ & $\mathrm{OK}$ & $\mathrm{OK}$ \\
& & & & & & & &
\end{tabular}

Sumber; Analisis Eurocode

\section{Kesimpulan}

Berdasarkan hasil perhitungan analisis dan pembahasan pada penelitian tentang Analisis Perbandingan Penurunan Pondasi telapak pada empat Lokasi. Maka dapat diambil beberapa kesimpulan, hasil analisis menggunakan data tanah terdahulu dari laboratorium PU kabupaten sukabumi, dan data pembebanan yang dihasilkan dari analisis pembebanan rumah dua lantai dapat disimpulkan bahwa Dimensi pondasi telapak memenuhi syarat aman berdasarkan data parameter tanah $(\gamma$ dan $c)$ dan data sondir dengan dimensi $\mathrm{L}=1,6 \mathrm{~m} \mathrm{~B}=1,6 \mathrm{~m} \mathrm{Df}=2 \mathrm{~m}$. Berdasarkan hasil analisis daya dukung pondasi terhadap tanah Desa Bojong, Cicantayan, Kp. Pamoyanan, Desa Banyuwangi Kec. Cibitung, Kp. Cibarengkok Desa Cidadap Kec. Simpenan, Kp. Cikaramat, Desa Sukamanis Kec. Kadudampit dengan menggunakan data sondir parameter tanah, dan beban aksial (P) sebesar $155,254 \mathrm{kN}$ memiliki daya dukung rencana yang lebih kecil dari daya dukung aktual, maka daya dukung pondasi telapak memenuhi syarat. Berdasarkan hasil perhitungan penurunan pondasi segera menunjukan bahwa penurunan paling tinggi terjadi di Kp. Cikaramat, Desa Sukamanis Kec. Kadudampit dengan nomor sampel TB 3-02 1 sebesar 1,01 mm dan penurunan terkecil terdapat pada Desa Bojong Cicantayan sebesar 0,101 mm. Faktor keamanan pondasi yang terjadi akibat beban kerja diatasnya yang di asumsikan dengan bangunan rumah 2 lantai dengan nilai $\mathrm{Vu}=155 \mathrm{Kn}, \mathrm{Mx}=1,7468 \mathrm{kN} / \mathrm{m}, \mathrm{My}=31,8259 \mathrm{kN} / \mathrm{m}$ dihasilkan pada Desa Bojong, Cicantayan pada sampel $1=7,17$ sampel 2=6,5. Kp. Pamoyanan, Desa Banyuwangi Kec. Cibitung sampel 1=5,5 sampel 
$2=7$. Kp. Cibarengkok Desa Cidadap Kec. Simpenan sampel 1=5,4 sampel 2=8,08. Kp. Cikaramat, Desa Sukamanis Kec. Kadudampit sampel 1=4,42 sampel 2=9. Untuk memastikan terhadap daya dukung pondasi melalui perhitungan manual maka dilakukan ananlisis menggunakan aplikasi Eurocode, output dari aplikasi tersebut menunjukan bahwa nilai tegangan maksimum lebih kecil daripada tegangan ijin.

\section{Daftar Pustaka}

[1] M. R. Rojib, "Alternatif perencanaan pondasi pada proyek pembangunan jembatan baja Sungai Rasau Kecamatan Bumi Makmur Kabupaten Tanah Laut." Universitas Islam Kalimantan MAB, 2021. Available at: Google Scholar.

[2] E. Kalogo, K. R. Bela, and P. Sianto, "Analisis Penurunan Segera pada Pondasi Telapak Berdasarkan Nilai Daya Dukung Terzaghi, Mayerhof, Brinch Hansen, dan Vesic," J. Tek. SIPIL ITP, vol. 8, no. 1, pp. 15-22, 2021. Available at: Google Scholar

[3] I. W. Redana, A. M. Hidayati, and A. A. N. D. Paramartha, "Uji plate loading terhadap daya dukung dan penurunan pada pondasi telapak dengan dan tanpa menggunakan geotekstil di atas tanah lempung," $J$. Spektran, vol. 8, no. 2, p. 149, 2020. Available at: Google Scholar

[4] H. Kusumah and H. Hartono, "Analisa Daya Dukung Dan Penurunan Tanah Terhadap Pondasi Telapak Di Pembangunan Ruko JI Pelabuhan li Kota Sukabumi," Santika J. Ilm. Sains dan Teknol., vol. 8, no. 2, pp. 787-796, 2018. Available at: Google Scholar

[5] H. H. Ahmad, "Analisis Daya Dukung Tanah Pada Pondasi Dangkal Dengan Metode L Heminier Dan Meyerhof," J. Penelit. IPTEKS, vol. 6, no. 1, pp. 1-5, 2021. doi: 10.32528/ipteks.v6i1.4171

[6] R. K. Umam and A. Kalista, "Analisa pengendalian kualitas statistik dengan menggunakan metode statistical process control di PT. XYZ," MathVisioN, vol. 3, no. 1, pp. 28-37, 2021. Available at: Google Scholar

[7] A. Kartika and C. A. Sirega, "Analisis nilai CBR rencana dengan metode uji DCP (Dynamic Cone Penetration) dan metode uji CBR laboratorium (rendaman) pada proyek jalan tol Cileunyi-SumedangDawuan (Cisumdawu) fase 2," in Prosiding SoBAT (Seminar Sosial Politik, Bisnis, Akuntansi dan Teknik) Universitas Sangga Buana YPKP, 2020, pp. 44-60. Available at: Google Scholar

[8] I. Irwansyah and S. Hendri, "Analisis jenis pondasi gedung Mesjid Agung Kota Tanjung Balai," JUITECH J. IIm. Fak. Tek. Univ. Qual., vol. 5, no. 1, pp. 27-33, 2021. Available at: Google Scholar

[9] K. Fadli, "Perbandingan daya dukung ultimit tiang pancang berdasarkan data spt dengan hasil kalendering pada abutment jembatan (Studi Kasus: Proyek Penggantian Jembatan Sungai Berangas (Ray 2))." Universitas Islam Kalimantan MAB, 2021. Available at: Google Scholar

[10] A. Y. Trinanda, "Tinjauan daya dukung pondasi sumuran pada gedung-x di kota Bukittinggi," J. RIVET, vol. 1, no. 01, pp. 26-31, 2021. Available at: Google Scholar 